\title{
Avaliação da eficiência térmica de telha reciclada à base de embalagens longa vida
}

\author{
Juliano Fiorelli', José A. B. Morceli', Rodrigo I. Vaz ${ }^{1} \&$ Antonio A. Dias ${ }^{2}$
}

\begin{abstract}
RESUMO
Neste trabalho se apresenta o estudo da influência de telha reciclada à base de embalagens longa vida (IBAPLAC ${ }^{\circledR}$ ) no conforto térmico de instalações zootécnicas. A pesquisa foi desenvolvida no Campus Experimental da Unesp de Dracena, SP. Foram construídos quatro protótipos, com área de $28 \mathrm{~m}^{2}$ cada um, sendo um deles coberto com telha reciclada à base de embalagens longa vida e três protótipos de referência cobertos com telha cerâmica, telha cerâmica pintada de branco e telha de fibrocimento (Brasilit ${ }^{\circledR}$ ). Dentro dos protótipos foram instalados termômetros de globo negro e termômetros de bulbo seco e bulbo úmido. Os dados foram coletados no verão de 2006/2007, totalizando 90 dias. Uma análise estatística por inferência e descritiva foi realizada utilizando-se valores médios de índice de temperatura de globo e umidade, carga térmica radiante e índice de temperatura e umidade, referente ao período. Pelos resultados obtidos é possível afirmar que a telha reciclada apresentou índices de conforto térmico semelhantes àqueles encontrados para as telhas cerâmicas, podendo ser indicada como opção de cobertura para instalações zootécnicas.
\end{abstract}

Palavras-chave: ambiência, cobertura, índices do ambiente térmico

\section{Evaluation of the thermal efficiency of roof tiles made of recycled long-life packaging}

\begin{abstract}
This paper presents a study of the influence of roof tiles made of recycled long-life packaging (brand-name IBAPLAC ${ }^{0}$ ) on the thermal comfort of zootechnical facilities. The research was conducted at UNESP's Experimental Campus at Dracena, State of São Paulo, Brazil. Four prototypes were built, each with an area of $28 \mathrm{~m}^{2}$. One prototype was covered with roof tiles made of recycled long-life packing material and three reference prototypes were roofed with ceramic tiles, ceramic tiles painted white and fiber/cement tiles (Brasilit ${ }^{\circledR}$ ), respectively. Black globe thermometers and dry and wet bulb thermometers were installed inside the prototypes. Temperatures inside the structures were recorded in the Summer of 2006/2007 over a 90-day period. A descriptive statistical analysis was made, based on the mean values of black globe temperature and humidity index, radiant thermal load and temperature-humidity index of the period. The results obtained indicated that the thermal behavior of the recycled tile was similar to that of the ceramic tiles.
\end{abstract}

Key words: ambience, roofing, thermal environment indexes

${ }^{1}$ Campus Experimental de Dracena/UNESP. Rod. Com. João Ribeiro de Barros, km 651. CEP 17900-000, Dracena, SP. Fone: (18) 3821-8200; Fax: (18) 3821-8208. E-mail: fiorelli@dracena.unesp.br; maringa@click21.com.br; ibellivaz@dracena.unesp.br

2 Universidade de São Paulo. Av. Trabalhador São Carlense 400, CEP 13566-590, São Carlos, SP. Fone: (16) 3373-8200. E-mail: dias@sc.usp.br 


\section{INTRODUÇÃO}

Em virtude da sua extensão territorial e das condições favoráveis de clima e relevo, as atividades agrícolas e pecuárias brasileiras têm sido desenvolvidas em muitos estados, representando importante alternativa de investimento e produção. Evidencia-se, desta forma, o interesse de se intensificar a pesquisa voltada para o atendimento do homem do campo e de suas necessidades, enquanto participante fundamental dos processos produtivos (Ferreira, 1989).

Considerando-se que o Brasil está localizado a uma latitude de até $30^{\circ}$ sul, ou seja, na faixa mais quente do planeta, com médias de temperatura oscilando entre 20 a $25^{\circ} \mathrm{C}$ ao longo do ano, verifica-se que o Brasil inspira uma situação de maior cuidado com animais, referente ao estresse por calor que por frio.

As limitações para obtenção de altos índices zootécnicos no Brasil, decorrem do alojamento em ambientes com clima quente, de animais geneticamente desenvolvidos em climas mais amenos, em condições ou conceitos provenientes deste clima, daí a necessidade de se ter instalações adaptadas, com características construtivas que garantam o máximo possível de conforto, permitindo ao animal abrigado desenvolver todo o seu potencial genético. O ambiente, constituído do efeito combinado de condições (temperatura, umidade do ar, vento, radiação, luz, ruído, densidade animal, dentre outros), é considerado confortável quando a criação está em equilíbrio térmico com o meio, ou melhor, o calor produzido pelo metabolismo animal é perdido normalmente para o meio ambiente, sem prejuízo apreciável da produção (Baêta \& Souza, 1997); desta forma, as instalações rurais devem ser planejadas e construídas com a finalidade principal de diminuir a ação direta do clima (insolação, temperatura, vento, chuva e umidade do ar), que pode agir negativamente nos animais.

Do ponto de vista bioclimático, um dos principais fatores que influenciam na carga térmica de radiação incidente são os telhados, sobretudo em decorrência dos materiais de cobertura (Silva \& Sevegnani, 2001). Para Nääs et al. (2001) o telhado é o elemento construtivo mais significativo em uma instalação avícola, quanto ao controle da radiação solar incidente.

Jácome et al. (2007) avaliaram os índices de conforto térmico: índice de temperatura de globo e umidade (ITGU), carga térmica radiante (CTR) e umidade relativa do ar (UR) em galpões para poedeiras, cobertos com diferentes tipos de telha, localizados no nordeste do Brasil; como resultado, os autores afirmam que nos horários mais quentes a cobertura de telha cerâmica apresentou menor CTR quando comparada com os galpões cobertos com telha de cimento amianto e finalizam citando que este tipo de cobertura proporciona melhor conforto térmico para criação de frango de postura.

Nääs et al. (2001) avaliaram as características térmicas de telha de celulose e telha de fibrocimento com pintura de látex branca em um galpão avícola de densidade 12 aves $\mathrm{m}^{-2}$, no período de novembro a janeiro, construídos na orientação leste-oeste. Avaliando os índices médios de
CTR e ITGU, os autores chegaram à conclusão de que a telha de fibrocimento com uma demão de pintura branca, apresentou os maiores valores de umidade relativa às 8 h 30 min; já a telha à base de fibras de celulose mostrou os menores valores de temperatura de bulbo seco às 14 h 30 min. Quando avaliadas sob o ponto de vista de índices de CTR e ITGU, às $14 \mathrm{~h} 30 \mathrm{~min}$, o ambiente sob o telhado no qual foi utilizada a telha de fibrocimento indicou os piores valores. Não houve diferença estatística entre os ambientes resultantes dos dois tratamentos que utilizaram as telhas à base de fibra de celulose.

Trindade (2006) encontrou, em trabalhos na região semiárida paraibana, analisando o conforto térmico em galpões cobertos com telha de cimento-amianto, com e sem nebulização interna, nos horários mais quentes do dia (entre 10 e $14 \mathrm{~h}$ ), valores de temperatura ambiente e ITGU acima da zona de conforto térmico de poedeiras, mas afirma que esses valores não interferiram nos índices produtivos.

A realização de pesquisas que visem determinar índices de conforto térmico e tipos de materiais de cobertura mais adequados para instalações zootécnicas no meio rural, se mostra importante para garantir melhor conforto aos animais e, conseqüentemente, aumento da produção, mas o Brasil, país de dimensões continentais, apresenta uma variação climática bastante acentuada, tornando-se necessário o desenvolvimento de estudos regionais para mapear o comportamento de materiais de cobertura em instalações zootécnicas. Procurando propor a utilização de novos materiais de construção para o meio rural, o presente trabalho tem como objetivo avaliar a influência de telha reciclada, à base de embalagens longa vida (IBAPLAC ${ }^{\circledR}$ ), no conforto térmico de instalações zootécnicas localizadas na região Oeste do Estado de São Paulo e comparar seu desempenho com telhas cerâmicas, telha cerâmica pintada de branco e telha de fibrocimento.

\section{MATERIAL E MÉTODOS}

As construções em que se utiliza o novo material de cobertura, foram edificadas no Campus da UNESP de Dracena, SP, localizado a uma latitude de $21^{\circ} 29^{\prime}$ S, longitude $51^{\circ} 52^{\prime}$ 'W e altitude de $421 \mathrm{~m}$. O índice pluviométrico da cidade é de $1235,9 \mathrm{~mm}^{\mathrm{ano}}{ }^{-1}$ e o clima da região é do tipo Cwa, com inverno seco, segundo a classificação de Köppen. Quatro protótipos foram edificados, sendo um coberto com telha reciclada à base de embalagens longa vida (TR) e os outros três protótipos de referência cobertos com telha de fibrocimento (TFC), telha cerâmica (TC) e telha cerâmica pintada de branco, com tinta à base de PVA (TCB). Os protótipos possuíam 8,00 m de comprimento e 4,00 m de largura, totalizando uma área coberta de $28 \mathrm{~m}^{2}$ (Figura 1). O sistema estrutural foi executado em eucalipto roliço, pé direito de 3,00 m e cobertura com inclinação de 20\%. A maior dimensão foi locada no sentido leste-oeste. A telha reciclada à base de embalagens longa vida é fabricada comercialmente no Brasil, pela empresa IBAPLAC ${ }^{\circledR}$; trata-se de um material atóxico, com revestimento externo de alumínio que 
A.

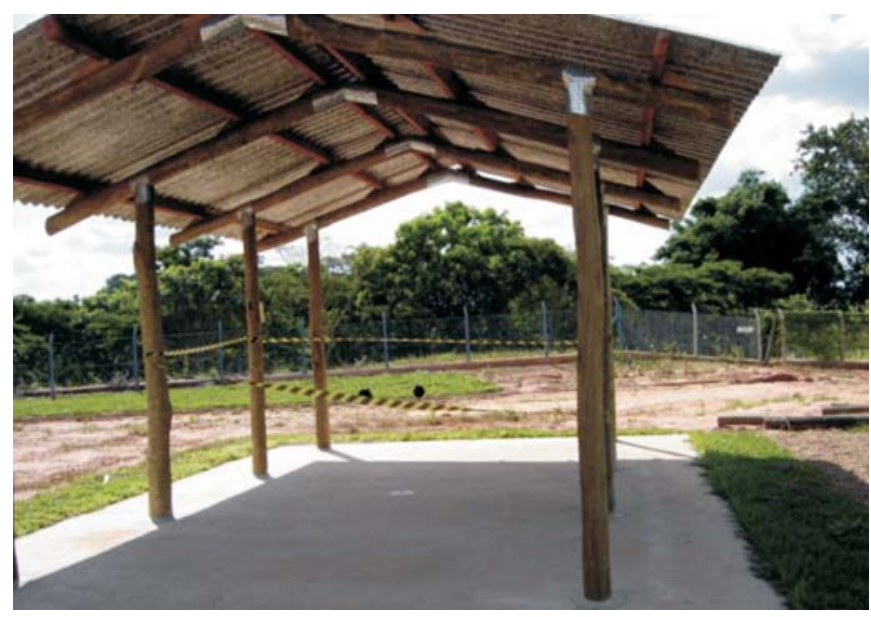

C.

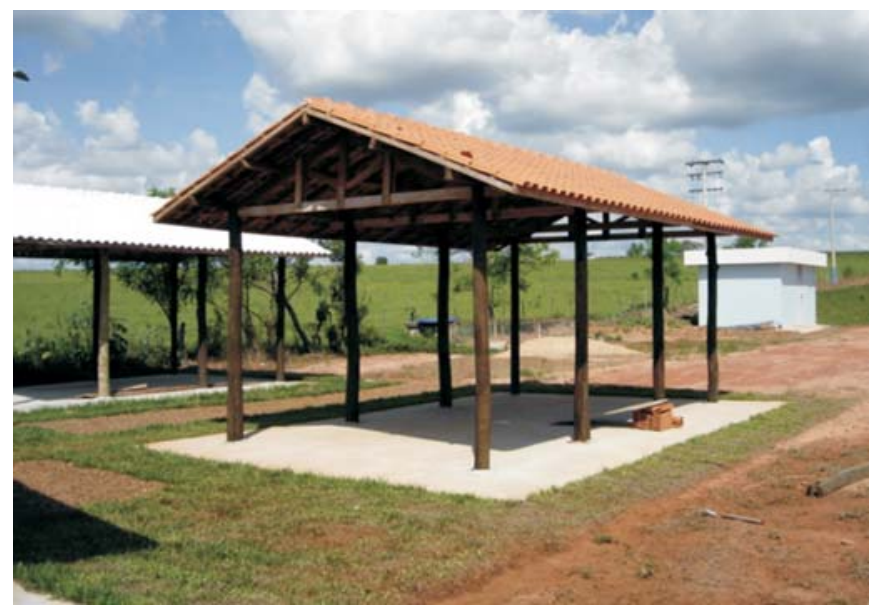

B.

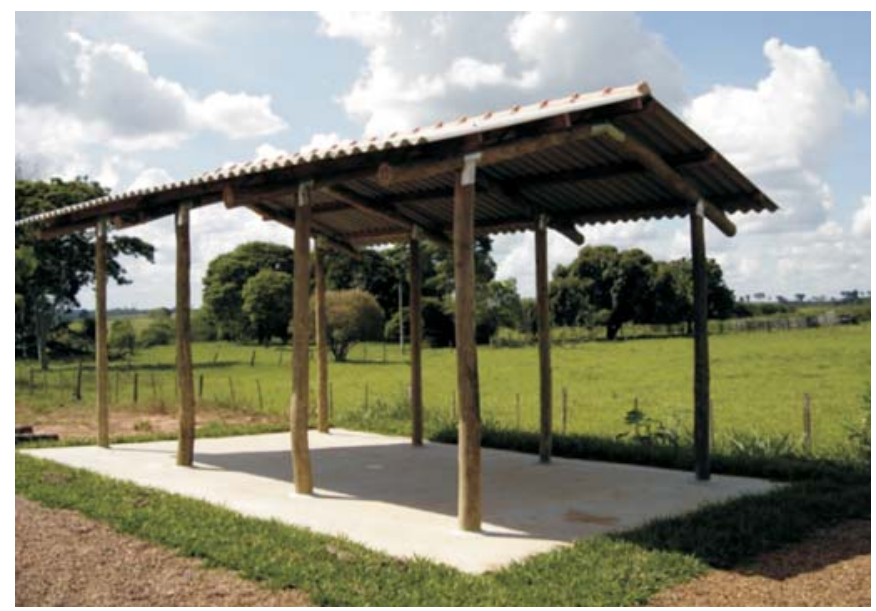

D.

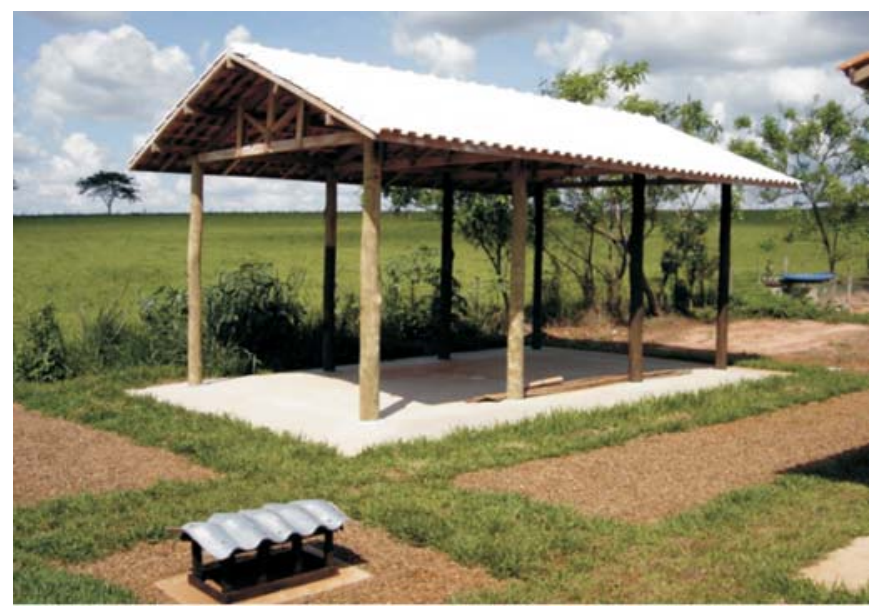

Figura 1. Protótipos avaliados: Telha reciclada (A), Telha fibrocimento (B), Telha cerâmica (C) e Telha cerâmica pintada de branco (D)

utiliza caixas do tipo tetrapack em sua composição e apresenta largura útil de $860 \mathrm{~mm}$, largura total de $920 \mathrm{~mm}$, comprimento de $2200 \mathrm{~mm}$, espessura $6 \mathrm{~mm}$ e peso de $14 \mathrm{~kg}$ (Figura 2).

Para se avaliar as coberturas foram instalados, em cada

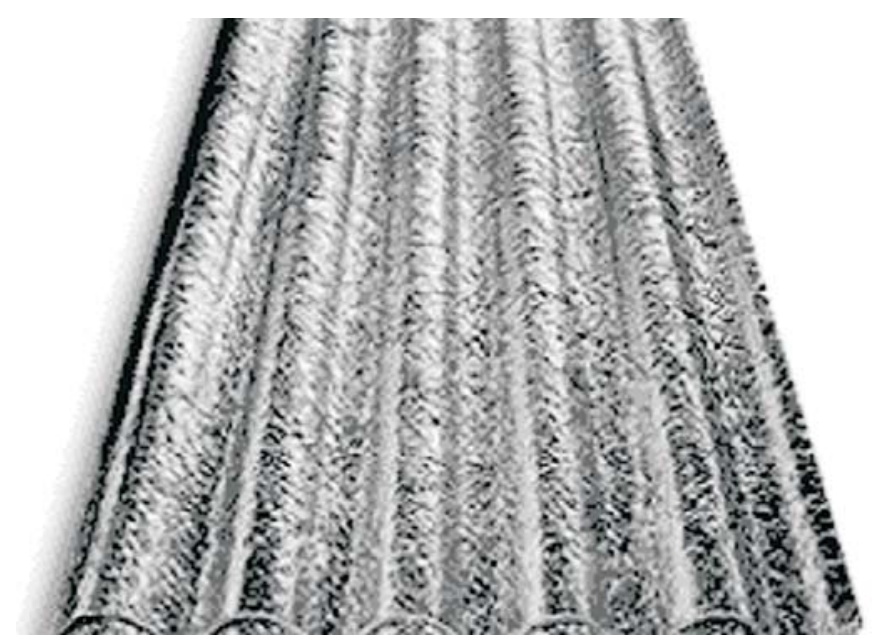

um dos protótipos, um termômetro de bulbo seco e bulbo úmido, dois termômetros de Globo Negro instalados a uma altura de $0,7 \mathrm{~m}$ e $1,5 \mathrm{~m}$ do piso e um anemômetro digital portátil. Para caracterizar o ambiente do experimento se utilizou uma estação metereológica da marca DAVIS, Vantage

Figura 2. Telha reciclada (IBAPLAC ${ }^{\circledR}$ - Revestimento externo de alumínio

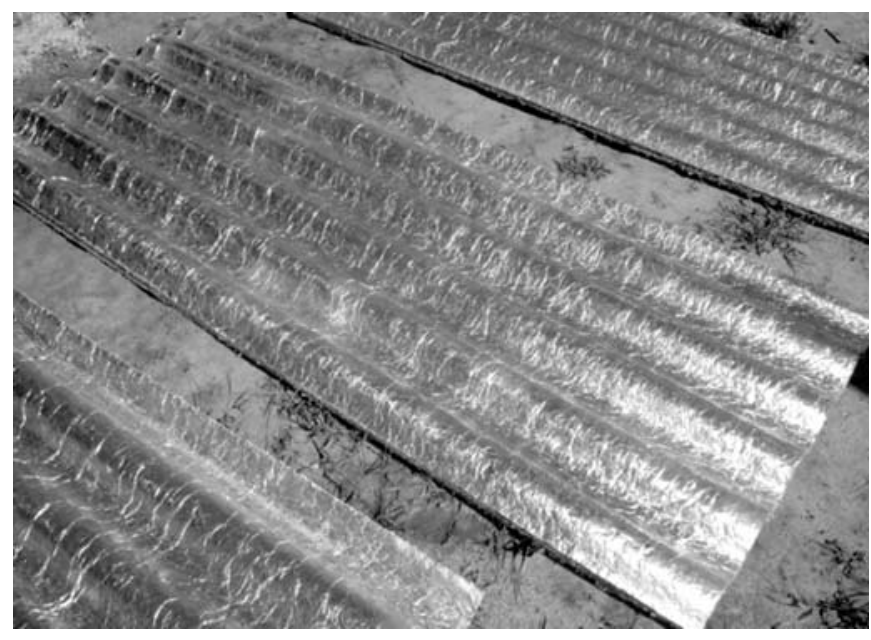


PRO2. As coletas foram realizadas nos horários das 10, 12, 14 e 16 h, durante o verão 2006/2007, totalizando 90 dias. Os índices ambientais analisados foram: índice de temperatura de globo e umidade (ITGU), carga térmica radiante (CTR) e índice de temperatura e umidade (THI). Esses índices foram determinados com base na temperatura ambiente, umidade relativa do ar, velocidade do vento e temperatura de globo negro, de acordo com as equações de Buffington et al. (1977), Esmay (1969) e Thom (1958), respectivamente. Realizou-se a análise estatística descritiva e por inferência determinando-se a média dos índices de conforto térmico (ITGU, CTR e THI), para cada um dos horários avaliados, referente a todo o período de análise, com as repetições sendo o número de dias do experimento. As médias foram comparadas por meio do teste de Tukey, adotando-se o nível de 1 e $5 \%$ de probabilidade.

\section{RESULTADOS E DISCUSSÃO}

Na Tabela 1 se apresentam os valores médios de índices de conforto térmico, referentes a todo o período de análise. Índice de temperatura de globo e umidade (ITGU), carga térmica radiante (CTR) e índice de temperatura e umidade (THI), para cada tipo de telha avaliada e os respectivos desvios padrões. A Figura 3 apresenta a variação do ITGU, CTR e THI em função dos horários avaliados, para a altura de 0,70 e 1,50 m, sendo os índices 1 , determinados com valores determinados a $0,70 \mathrm{~m}$ do piso e os índices 2 a $1,50 \mathrm{~m}$. O THI aparece apenas com um índice, pois foi determinado de acordo com a equação de Thom (1958), que considera temperatura de bulbo seco e de bulbo úmido, não sendo avaliado em diferentes alturas.

Os resultados obtidos pela análise estatística por inferência, utilizando-se o teste de Tukey, indicam que a CTR, referente à análise a 0,70 $\mathrm{m}$ do piso, apresentou diferença estatística significativa $(\mathrm{p}<0,05)$, entre as quatro coberturas analisadas para os horários das 14 h; já para a análise a 1,50 m do piso, houve diferença estatística significativa para os horários das $10 \mathrm{~h}$ e das 14 h, entre as TCB e TFC.

Analisando-se o valor médio da THI para o horário das 10 h, nota-se a existência de diferença estatística significativa $(\mathrm{p}<0,05)$.

Para os outros índices de conforto térmico e para os outros horários avaliados, a análise pelo teste de Tukey não indicou diferença significativa entre os valores, fato que pode ter ocorrido devido ao tamanho dos modelos e da exposição à radiação solar dispersa, principalmente em relação ao ITGU.

Observando-se a Figura 3 (A e B), é possível afirmar que o menor valor de ITGU referente à altura de $0,70 \mathrm{~m}$ do piso, foi encontrado no protótipo de TC; já para a altura de 1,50 m do piso, o menor ITGU foi determinado no protótipo de TCB, para todos os horários avaliados, enquanto o maior valor de ITGU, para todos os horários, foi identificado no protótipo coberto com TFC. Foi possível identificar um aumento no ITGU ao longo do dia, atingindo valor máximo às 14 h, para todas as coberturas avaliadas. ITGU semelhantes foram en-
Tabela 1. Valores médios* de Índice de Temperatura e Umidade (ITGU), Carga Térmica Radiante (CTR), Índice de Temperatura (THI) e Umidade e desvio padrão para diferentes tipos de telhas** estudados

\begin{tabular}{|c|c|c|c|c|}
\hline & TC & TCB & TR & TFC \\
\hline \multicolumn{5}{|c|}{$10 \mathrm{~h}$} \\
\hline ITGU 1 & 77,49 & 77,73 & 77,95 & 78,26 \\
\hline Desvio Padrão & $(2,38)$ & $(2,35)$ & $(2,37)$ & $(2,49)$ \\
\hline ITGU 2 & 77,79 & 77,51 & 77,84 & 78,08 \\
\hline Desvio Padrão & $(2,46)$ & $(2,32)$ & $(2,39)$ & $(2,44)$ \\
\hline CTR $1\left(\mathrm{~W} \mathrm{~m}^{-2}\right)$ & 503,98 & 511,11 & 526,23 & 526,23 \\
\hline Desvio Padrão & $(28,92)$ & $(29,06)$ & $(31,16)$ & $(31,75)$ \\
\hline CTR $2\left(\mathrm{~W} \mathrm{~m}^{-2}\right)$ & $511,36 \mathrm{ab}$ & $506,91 \mathrm{a}$ & $524,04 a b$ & $523,21 \mathrm{~b}$ \\
\hline Desvio Padrão & $(28,90)$ & $(25,45)$ & $(34,21)$ & $(28,86)$ \\
\hline $\mathrm{THI}$ & $75,19 \mathrm{ab}$ & $75,05 \mathrm{a}$ & $74,43 \mathrm{~b}$ & $74,80 \mathrm{~b}$ \\
\hline Desvio Padrão & $(8,01)$ & $(7,97)$ & $(7,91)$ & $(7,95)$ \\
\hline \multicolumn{5}{|c|}{$12 \mathrm{~h}$} \\
\hline ITGU 1 & 81,1 & 81,32 & 81,55 & 81,88 \\
\hline Desvio Padrão & $(3,25)$ & $(3,10)$ & $(3,16)$ & $(3,24)$ \\
\hline ITGU 2 & 81,35 & 81,03 & 81,46 & 81,77 \\
\hline Desvio Padrão & $(3,33)$ & $(3,10)$ & $(3,18)$ & $(3,24)$ \\
\hline CTR $1\left(\mathrm{~W} \mathrm{~m}^{-2}\right)$ & 541,86 & 543,19 & 557,94 & 560,98 \\
\hline Desvio Padrão & $(32,66)$ & $(30,95)$ & $(33,06)$ & $(35,81)$ \\
\hline CTR $2\left(\mathrm{~W} \mathrm{~m}^{-2}\right)$ & 550,21 & 535,86 & 555,79 & 558,43 \\
\hline Desvio Padrão & $(33,09)$ & $(28,90)$ & $(37,45)$ & $(33,36)$ \\
\hline THI & 78,15 & 78,48 & 78,01 & 78,29 \\
\hline Desvio Padrão & $(2,86)$ & $(7,86)$ & $(7,83)$ & $(7,86)$ \\
\hline \multicolumn{5}{|c|}{$14 \mathrm{~h}$} \\
\hline ITGU 1 & 82,84 & 83,08 & 83,25 & 83,71 \\
\hline Desvio Padrão & $(3,15)$ & $(2,93)$ & $(3,11)$ & $(3,14)$ \\
\hline ITGU 2 & 83,08 & 82,83 & 83,21 & 83,51 \\
\hline Desvio Padrão & $(3,20)$ & $(3,02)$ & $(3,17)$ & $(3,18)$ \\
\hline CTR $1\left(\mathrm{~W} \mathrm{~m}^{-2}\right)$ & $557,45 \mathrm{ab}$ & $558,7 \mathrm{a}$ & $572,04 \mathrm{abc}$ & $579,78 \mathrm{c}$ \\
\hline Desvio Padrão & $(32,54)$ & $(29,73)$ & $(35,69)$ & $(36,06)$ \\
\hline CTR $2\left(\mathrm{~W} \mathrm{~m}^{-2}\right)$ & $563,95 \mathrm{ab}$ & $552,19 \mathrm{a}$ & $570,88 \mathrm{ab}$ & $574,54 \mathrm{~b}$ \\
\hline Desvio Padrão & $(32,33)$ & $(29,50)$ & $(37,24)$ & $(34,90)$ \\
\hline THI & 80,01 & 80,24 & 79,83 & 80,05 \\
\hline Desvio Padrão & $(2,98)$ & $(8,06)$ & $(8,01)$ & $(8,03)$ \\
\hline \multicolumn{5}{|c|}{$16 \mathrm{~h}$} \\
\hline ITGU 1 & 82,67 & 82,97 & 83,13 & 83,44 \\
\hline Desvio Padrão & $(3,63)$ & $(3,50)$ & $(3,65)$ & $(3,71)$ \\
\hline ITGU 2 & 82,88 & 82,88 & 83,05 & 83,41 \\
\hline Desvio Padrão & $(3,73)$ & $(3,59)$ & $(3,76)$ & $(3,81)$ \\
\hline CTR $1\left(\mathrm{~W} \mathrm{~m}^{-2}\right)$ & 541,73 & 546,39 & 559,70 & 562,68 \\
\hline Desvio Padrão & $(34,41)$ & $(33,70)$ & $(39,35)$ & $(39,85)$ \\
\hline CTR $2\left(\mathrm{~W} \mathrm{~m}^{-2}\right)$ & 547,23 & 544,23 & 557,89 & 561,87 \\
\hline Desvio Padrão & $(35,54)$ & $(35,42)$ & $(40,88)$ & $(41,28)$ \\
\hline THI & 80,40 & 80,57 & 80,10 & $\begin{array}{l}80,35 \\
\end{array}$ \\
\hline Desvio Padrão & $(3,41)$ & $(8,22)$ & $(8,17)$ & $(8,20)$ \\
\hline
\end{tabular}

* Letras diferentes indicam diferença significativa a $5 \%(p<0,05)$; ** TC - Telha cerâmica, TCB - Telha cerâmica pintada de branco, TR - Telha reciclada, TFC - Telhas de fibrocimento

contrados nos protótipos cobertos com TR e TC para as alturas e os horários avaliados. O fato de não ter sido identificada diferença estatística significativa entre os ITGU, indica que a TR pode ser uma nova opção de material para cobertura, uma vez que possui comportamento semelhante as das telhas tradicionais.

O resultado encontrado é coerente com o relatado por Silva et al. (1990), ao avaliarem telha cerâmica e telha de cimento amianto, com camada dupla e colchão de ar de $5 \mathrm{~cm}$, mostraram que nos horários de maior incidência solar não ocorreu diferença significativa a nível de 5\% de 

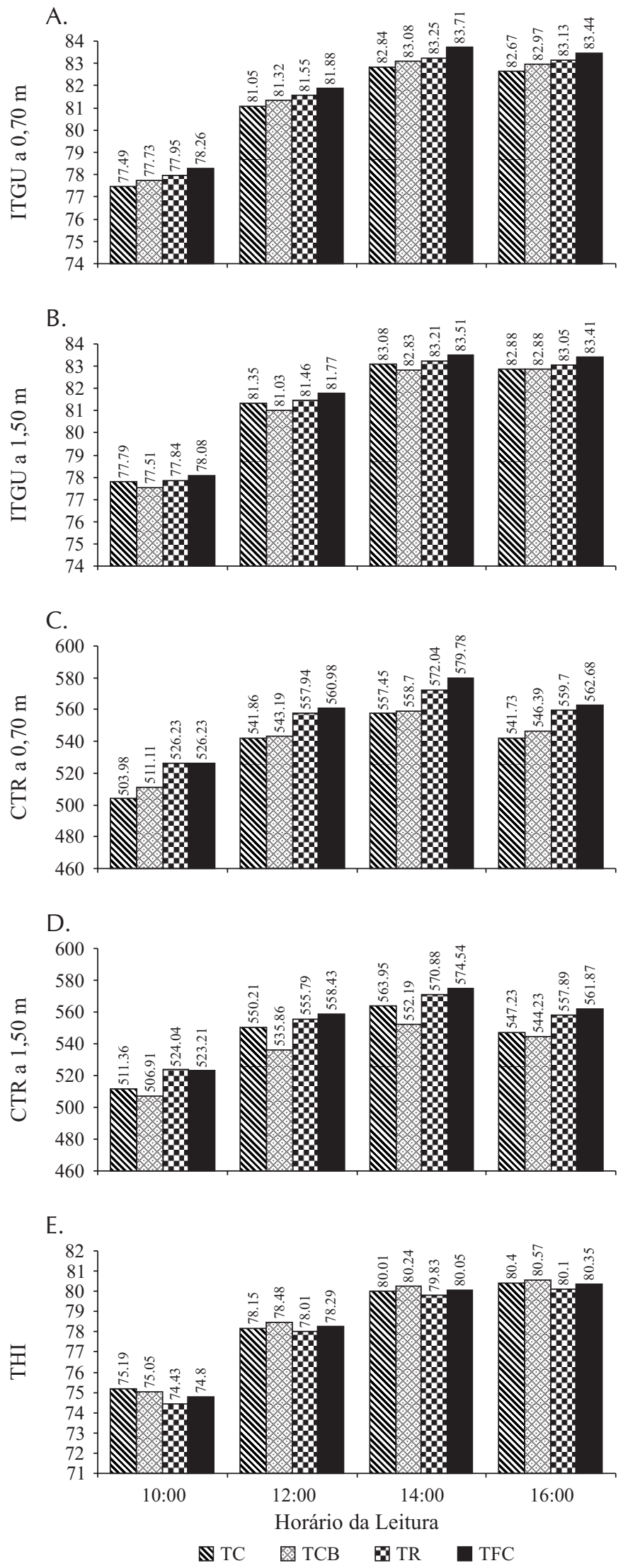

Figura 3. Valores médios do Índice de Temperatura do Globo e Umidade (ITGU) - A e B, da Carga Térmica Radiante (CTR) - C e D e de Índice de Temperatura e Umidade (THI) - E referentes às coberturas de Telha cerâmica (TC), Telha cerâmica pintada de branco (TCB), Telha reciclada (TR) e Telha fibrocimento (TFC) em diferentes horários probabilidade $(\mathrm{p}<0,05)$ para o ITGU referente às duas coberturas; pode-se, portanto, observar (Figura 3 A e B) que para as duas alturas avaliadas o protótipo coberto com TR apresentou ITGU intermediário entre a cobertura de TC e TFC, demonstrando a eficiência do material para cobertura de instalações zootécnicas.

Resultados semelhantes aos apresentados foram obtidos por Gomes et al. (2008), que avaliaram ITGU e CTR em apriscos cobertos com telha de barro, localizados no semiárido nordestino. Os autores relataram valores médios de ITGU variando de 73,7 (7 h) a 85,9 (15 h).

De acordo com o National Weather Service, apud Gomes et al. (2008), valores de ITGU até 74 , de 74 a 78 , de 79 a 84 e acima de 84, definem situação de conforto, de alerta, de perigo e de emergência, respectivamente para bovinos. De acordo com os dados encontrados, neste trabalho, para os horários avaliados, as coberturas colocam os animais em situação de perigo e emergência.

Observa-se na Figura 3 (C e D), um aumento no valor da CTR ao longo do dia para todas as coberturas avaliadas, atingindo valor máximo às $14 \mathrm{~h}$. Os menores valores de CTR foram identificados no protótipo coberto com TC, a 0,70 m e no protótipo coberto com TCB, a 1,50 m do piso, para todos os horários avaliados; já os maiores valores de CTR foram identificados no protótipo coberto com TFC, porém se nota uma diferença estatística significativa $(\mathrm{p}<0,05)$ entre os valores de CTR referentes à cobertura de TCB e TFC. Em relação ao protótipo coberto com TR, não se identificou diferença estatística significativa de CTR com o protótipo coberto com TC; este resultado indica a eficiência da respectiva telha em análise. De forma geral, para as alturas de $0,70 \mathrm{~m}$ e 1,50 m o protótipo coberto com TR apresentou CTR intermediário entre a cobertura de TC e TFC.

Silva et al. (1990) analisaram o valor do CTR de cobertura cerâmica e cimento amianto e concluíram que, no período avaliado, a CTR era semelhante, com diferença de até $5 \%$, resultado análogo ao apresentado no trabalho. Campos (1986) estudou a influência de três materiais de cobertura sobre o índice de conforto térmico, em condições de verão para Viçosa, MG, e concluiu que para o dia típico de céu descoberto, com 12,3 h de brilho solar, a maior eficiência na redução do CTR e as melhores condições de conforto térmico foram obtidos sob cobertura de telha cerâmica, enquanto o pior desempenho foi para cobertura de cimento-amianto.

Furtado et al. (2003) analisaram galpões cobertos com telha cerâmica e amianto e identificaram que os valores de CTR sob coberturas de telha de amianto são superiores aos de telha cerâmica, resultado semelhante ao encontrado neste trabalho.

Em relação ao THI, o protótipo coberto com TR apresentou os menores índices para todos os horários avaliados. No entanto, de acordo com as indicações de Thom (1958), todas as coberturas apresentaram THI acima daquele considerado ideal para criação animal de interesse zootécnico, ou seja, fora da zona de conforto térmico. Sendo assim, animais alojados nas instalações em análise estão submetidos a condições de desconforto térmico. 


\section{CONCLUSÕES}

1. Os índices de conforto térmico, determinados sob as coberturas dos galpões cobertos com telha reciclada, telha cerâmica, telha cerâmica pintada de branco na face externa, telha de fibrocimento, na maioria dos horários estudados, tiveram comportamentos semelhantes e não apresentaram variação significativa a $5 \%$ de probabilidade, mas se identificou a existência de diferença estatística significativa entre a CTR e o THI das TCB e TFC.

2. A telha reciclada pode ser uma opção de cobertura para ser utilizada em instalações zootécnicas, uma vez que apresentou índices de conforto térmico semelhantes aos outros materiais de cobertura em análise. Além disso, esta telha é um material sustentável, fabricado a partir de resíduos de caixas tetra pack.

\section{AGRADECIMENTOS}

Os autores agradecem à FAPESP e ao CNPq, pelo apoio à pesquisa.

\section{LITERATURA CITADA}

Baêta, F. C.; Souza, C. F. Ambiência em edificações rurais - conforto animal. Viçosa: UFV, 1997, 246p.

Buffington, D. E.; Collaso-Arocho, A.; Canton, G.; Pitt, D.; Thatcher, W. W.; Collier, R. J. Black globe humidity comfort index for dairy cows. St. Joseph: ASAE 77-4517, 1977. 19p.

Campos, A. T. Determinação dos índices de conforto e da carga térmica de radiação em quatro tipos de galpões, em condições de verão para Viçosa, MG. Viçosa: UFV, 1986. 66p. Dissertação Mestrado
Esmay, M. L. Principles of animal environment. 2.ed. West Port CT: ABI Publishing, 1969. 325p.

Ferreira, L. A. Diretrizes arquitetônicas nas instalações para bovinos. São Carlos: USP, 1989. 241p. Dissertação Mestrado

Furtado, D. A.; Azevedo, P. V.; Tinoco, I. F. F. Análise do conforto térmico em galpões avícolas com diferentes sistemas de acondicionamento. Revista Brasileira de Engenharia Agrícola e Ambiental, v.7, n.3, p.559-564, 2003.

Gomes, C. A. V.; Furtado, D. A.; Medeiros, A. N.; Silva, D. S.; Pimenta Filho, E. C.; Lima Junior, V. Efeito do ambiente térmico e níveis de suplementação nos parâmetros fisiológicos de caprinos Moxotó. Revista Brasileira de Engenharia Agrícola e Ambiental, v.12, n.2, p.213-219, 2008.

Jácome, I. M. T. D.; Furtado, D. A.; Leal, A. F.; Silva, J. H. V.; Moura, J. F. P. Avaliação de índices de conforto térmico de instalações para poedeiras no nordeste do Brasil. Revista Brasileira de Engenharia Agrícola e Ambiental, v.11, n.5, p.527-531, 2007.

Nääs, I. A.; Sevegnani, K. B.; Marcheto, F. G.; Espelho, J. C. C.; Menegassi, V.; Silva, I. J. O. Avaliação térmica de telhas de composição de celulose e betumem, pintadas de branco, em modelos de aviários com escala reduzida. Engenharia Agrícola, v.21, n.2, p.121-126, 2001.

Silva, I. J. O.; Guelfi Filho, H.; Consigleiro, F. R. Influências dos materiais de cobertura no conforto térmico de abrigos. In: Congresso Brasileiro de Engenharia Agrícola, 19, 1990, Piracicaba. Anais... Piracicaba: SBEA, 1990. p.93-106.

Silva, I. J. O.; Sevegnani, K. B. Ambiência na produção de aves de postura. In: Silva, I. J. O. Ambiência na produção de aves em clima tropical. Piracicaba: FUNEP, p.150-214. 2001.

Thom, E. C. Cooling degree: day air conditioning, heating, and ventilating. Transaction of the American Society of Heating, v.55, n.7, p.65-72, 1958.

Trindade, J. L. Diagnóstico ambiental e índices zootécnicos em galpões de poedeiras no semi-árido paraibano. Campina Grande: UFCG, 2006. 68p. Dissertação Mestrado 